\title{
Empirical Analysis of Posts and Interactions: A case of Australian Government Facebook Pages
}

\author{
Sultana Lubna Alam \\ School of Information Systems and Accounting \\ Faculty of Business, Government and Law \\ University of Canberra, Australia \\ Lubna.Alam@canberra.edu.au
}

\begin{abstract}
Research on government use of Facebook (FB) and citizen engagement has increased in the last five years or so; however there is a scarcity of empirical research that identify the extent of agency and audience engagement on government $F B$ pages. Questions still remains unanswered if agencies with dissimilar functional focus engage differently in FB. Based on a large-scale world-first empirical analysis of over 147 federal government FB pages, this article presents insights on online participation in terms of government posts and citizen interactions observed over three years (2013-2016) across different types of agencies (i.e. operational, policy, regulatory and specialist). Preliminary findings show convincing agency and audience engagement on FB pages as a platform for sharing and communicating. However there are differences among the agencies in terms of audience and agency engagement relative to post activity and interactions. The findings have implications for federal government agencies, both from benchmarking and capability building perspectives.
\end{abstract}

Keywords: Facebook, government, post, interaction 


\section{Introduction}

Governments around the world have become significant users of Facebook for public engagement over the last decade. Government SNS (social networking sites) and Facebook (FB) adoption represents a trend with potential to impact broad regulatory and public administration processes. Digital media and SNS have enhanced citizen information accessibility, government-citizen engagement and networking, and altered the way citizens socialize with one another and government; government SNS adoption represents an evolutionary implication for democratic engagement (Dixon, 2010; Linders, 2012; McKnutt, 2014). With citizens projected to increasingly expect government involvement, for administrators, "keeping pace with new is critical to governments committed to knowledge-based economies that simultaneously foster innovation and promote social cohesion" (McKnutt, 2014, p. 49). The U.S and Australian government's Open Government Initiative (Linders, 2012; Chun, 2012; Alam and Walker, 2011) and the U.K government's Big Society Project represent initiatives for advancing social media (SM) government use and citizen engagement, with such initiatives seeking to devolve power to citizens and enhance collaboration. Efforts by governments to increase coproduction and collaboration through SNS adoption constitute "an extension of the current digitisation efforts of government services as a new wave of the e-Government era" (Mergel, 2013a, p. 328). Governments can engage in multiple models with citizens including G2C, C2G and even $\mathrm{C} 2 \mathrm{C}$. These models are similar to commerce and business models where agencies are attempting to meet the demands of their customers (i.e. citizens). The new public policy (NPP) principles advocate that government agencies are non-profit making revenue generating organisations and thus have similarities with private sector organisations.
Despite the prevalence of moves towards increased adoption, and initiatives in place to foster greater citizen engagement, and coproduction, research suggests "the dialogic affordances of social media remain underutilized by public relations and even democratic governments" (Heaselgrave and Simmons, 2016, p. 133). SNSs are used to complement existing communication platforms, both online and offline, and do not serve to usurp or replace e-government services (Mergel, 2013a, p. 328). Researchers have found that practitioners are using [SNS] for one-way transmission of information, as "information dumps" (e.g., Abdelsalam et al., 2013; Lee, 2014; McKnutt, 2014; Mergel, 2013b; Mossberger et al., 2013; Reddick and Norris, 2013; Soon and Soh, 2014). This indicates there is a gap between theoretical knowledge and practical application of government SNS use, with "[m]any federal departments and agencies [...] still in the middle of navigating the uncertainties of using social media as an extension of the use of their online presence" (Mergel 2013a, p. 328). Lack of empirical data about government FB engagement and use of social media for two-way communication led to call for research that explores the dynamics involved in social media use. In Australia, where research into federal government is limited (Alam et al., 2011, Heaselgrave and Simmons, 2016), there are few scholarly contributions to understanding the practical application of social media engagement. Further, there is a lack of large-scale empirical research on government agencies and their interactions with citizens through the use of FB pages. Majority of research in this area is based upon anecdotal cases of successful government implementations or interviews with government communicators; and focused on large populated cities or local level government (e.g. Councils). Hence research on FB in government is still in its infancy, fragmented and does not focus on different levels of government. However there is considerable differences among government relative to their functional areas (e.g. operational, policy or 
regulatory). It is asserted that government agency interactions on social media (i.e. Facebook) will vary based upon the functional areas of the government. This research aims to fulfil this gap.

The focus of this research is thus back on the federal government, particularly, how federal government is engaging on FB and what insights this can provide in terms of transforming government service delivery to better meet the needs of their different functions (e.g. policy, regulatory or operational). This research examines the extent of 147 Australian federal government uses of FB services in terms of citizen interactions with government posts. Specific research question that guide this research is: Are there any differences in audience interactions with government posts for different types of agencies?

From a theoretical perspective, the research will generate insights on interactions and engagement with government posts for different types of agency and fill a gap at both empirical and theoretical level. From a practical perspective, the research will contribute new knowledge particularly for Australian federal government agencies, engagement strategies for post activity relative to citizen interaction. This will further assist in their efforts to benchmark against similar others and in identification of capability gaps in government interactions with citizens on FB pages.

\section{Facebook in Government Research}

Current literature in SNS government adoption has grown worldwide, and increasing research has been undertaken in the field in the past five years, including in Australia (Alam and Walker, 2011; Alam and Diamah, 2011; Alam et al., 2011; Collins, 2009; Samuel, 2009; Skeels and Grudin, 2009; Howard, 2012; Heaselgrave and Simmons, 2016) and U.S (Mossberger et al., 2013; Snead, 2013). Research undertaken in the government SNS space has tended to be descriptive and explanatory, analyzing singular or multiple government SNS usage cases, and/or of the technological developments and implications of SNS adoption for citizen engagement and governmentality (Mergel, 2013a, p. 329). Results from such exploratory and empirical papers have found that, while e-government has been adopted by government services with great interest, outcomes of increased engagement and efficiency regarding costeffectiveness and downsizing have yet to be realized ( $p$. 329). There is still confusion regarding appropriate strategies for public sector FB use (Hofmann et al., 2013; McKnutt, 2014, p. 51; Warren et al., 2014).

Empirical and conceptual works in SNS government use reveal prevalence of particular findings. Results suggested governments increasingly employed FB as a communicative device, yet strategies were often misguided and FB underutilised (e.g., Alam and Walker, 2011; Al-Wahaibi et al., 2015; Kavanaugh et al., 2012; McKnutt, 2014; Mossberger et al., 2013), with oneway 'push' communications employed (Abdelsalam et al., 2013; Lee, 2014; McKnutt, 2014; Mergel, 2013a; Mossberger et al., 2013; Reddick and Norris, 2013; Soon and Soh, 2014). Concern with citizen engagement is arguably prevalent due to the general consensus that citizen engagement with SM indicates prevalence of interactivity, with social media channels understood not only to perform functions of "mass dissemination but also [...] mass production and collaboration" (Linders, 2012, p. 446; Mainka et al., 2014). Increased government-consumer interactivity constitutes a goal of government SM use (Criado et al., 2013).

There is an increased scholarly interest in smart cities in government research. Studies considered implications of SM use by nations (Alam and Walker, 2011) or municipalities (Hartmann et al., 2013) and their impact within the context of population and tourism. For example, Lev-On and Steinfeld's (2015) results supported their 
hypothesis that correlated "municipal-level FB adoption [with] population size, location $[\ldots .$.$] , as well as age, income, and education$ of the population" (p. 301). These studies were concerned with whether FB popularity for city pages resulted from effective SM communications or were due to general city popularity (e.g., Paris over Helsinki; Hartmann et al., 2013; Sáez-Martin et al., 2014; Mainka et al., 2015). Prevalence of population and tourism context-based articles (determined by agency-type studied) suggests the wide empirical applicability of government $\mathrm{SM}$; another identified emerging agency-type category were department campaigns and initiatives (Lee, 2014; Soon and Soh, 2014) rather than agency-wide FB pages, though this applied to a small selection of studies within the Asian region. However no research took a holistic approach to empirically examine post and interaction activities and behavioural patterns across a large sample. There is evidence to suggest that government agencies engage differently in FB pages however no research has examined this identified gap. This research is an attempt to contribute to this gap.

\section{Theoretical Foundations}

The capacity for scholars to adequately measure and evaluate these activities has been limited due to the fragmented nature of research; the literature has "yet to come together in a coherent and cohesive fashion" (Linders, 2012), with common measurement types yet to be cemented (Criado et al., 2013). Linders (2012) argues that "a common typology [is needed] for understanding, comparing, and guiding implementations" of coproduction and engagement in government social media" ( $p$. 447). There has been comparatively few conceptually-oriented research, and those papers that have sought to categorize or thematically conceptualize frameworks to better understand the SNS government space have tended to approach such conceptual tasks differently. . Linders' (2012) categorisation tended towards coproduction focus for social media use in government, with the division of three categories: citizen sourcing (C2G) (citizen consultation to improve representation and government responsiveness), government as a platform (G2C) ('nudging' of citizens by government to become informed and engaged), and 'do it yourself' government (C2C) (the selforganisation of citizens with little government interference) (p. 449). Criado et al. (2013), comparatively, developed three topic $s$ relative to innovation and implementation for SM in government: tools (relating to communication platforms), goals (organisational ends or objectives of SM usage), and topics (including predominant themes, methods, level of government, and country or region of extant research). Despite these efforts, there remains a great deal of work to understand the dynamics in terms of interactions and engagement with citizens (Criado, Rojas-Martin and GilGarcia, 2017). This study develops a deeper understanding about social media in public administration, particularly in terms of interactions and posting behavior among different agency types and seeks to fill a gap at both theoretical and empirical levels.

In the absence of holistic models to analyse social media in government (Criado, RojasMartin and Gil-Garcia, 2017), we use two theoretical streams of literature to first understand the interaction between government and citizen (Mergel, 2013b) and second to explain the differences between agency types from a neo-institutional model perspective (Gil-Garcia, 2012, Criado, Rojas-Martin and Gil-Garcia, 2017).

Mergel (2013a) devised a framework for social media interactions around citizen engagement and impact based upon Open Government Initiative (OGI) by US government. Mergel provides a social media impact framework (pp. 330-331) with three interaction levels for social media interactions in public sector (see Table 1 which lists related mechanics for Facebook). We found this framework to align well with open government declaration of Australian government as proposed by the Gov 2.0 taskforce (DTO, 2009). Hence we chose 
this framework as the basis for analysing Facebook interactions and associated measurements for analysing Australian government Facebook pages for this study.

\begin{tabular}{|c|l|l|}
\hline \multicolumn{2}{|c|}{\begin{tabular}{c} 
Table 1 - Measuring Facebook interactions in the public sector \\
\hline $\begin{array}{c}\text { Mission and } \\
\text { Interaction } \\
\text { level }\end{array}$
\end{tabular}} & \multicolumn{1}{|c|}{ Measurement goal for Facebook } \\
\hline Transparency & $\begin{array}{l}\text { Information and education with implications for } \\
\text { representation and citizen information accessibility } \\
\text { through Facebook for accountability and trust }\end{array}$ & $\begin{array}{l}\text { Number of fans, Number of likes } \\
\text { for posts }\end{array}$ \\
\hline Participation & $\begin{array}{l}\text { Engagement measurement practices for citizen } \\
\text { engagement with government-facilitated communication } \\
\text { for consultation and satisfaction }\end{array}$ & $\begin{array}{l}\text { Post types and post frequency, } \\
\text { comments and likes on Facebook }\end{array}$ \\
\hline Collaboration & $\begin{array}{l}\text { co-creation and public-government relationship } \\
\text { management through community building and creation } \\
\text { of issue networks }\end{array}$ & $\begin{array}{l}\text { Shares on Facebook to others or } \\
\text { issue networks }\end{array}$ \\
\hline
\end{tabular}

A neo-institutional model of enacting electronic government success (EEGS) by Gil-Garcia (2012), which draws heavily on Fountain's work on technology enactment framework, posits that institutional arrangements and organisational forms moulds the selection, design, implementation and use of ICTs in the public administrations. As a result, "it is not surprising, therefore, that similar organisations may use identical information systems in vastly different ways" (Fountain, 2001, p.89 cited in (Criado, Rojas-Martin and Gil-Garcia, 2017). Hence extending EEGS model to social media use in government, Criado, Rojas-Martin and GilGarcia (2017) proposes that social media outcomes in public administration is dependent on exogenous factors such as institutional factors (e.g. legal, regulation, control), organizational factors (e.g. size, training, strategic plan) and environmental factors (e.g. political, demographic, economic, technological). This analytical framework can serve as a useful lens for this research to provide an explanatory lever to explain differences in interactions and posting behavior among different agency types.

\section{Methodology}

The study is part of a larger study that utilised a three-stage, exploratory mixed methods research design. Mixed methods research understands that quantitative and qualitative research, when combined, allow for a better understanding of the problem than quantitative or qualitative approaches alone (Creswell and Clark, 2007). The three stages of the research are:

- Stage 1 Quantitative data analysis: Using the FB API through a third party data mining tool - Crowdtangle, FB page data was collected for all federal Australian Government FB Pages (147 in total). A quantitative data analysis was carried out based on Mergel's (2013b) framework by measuring page fan size, page posting frequency, post types (video, photo, etc.), and interaction types between 2013 -2016.

- Stage 2 Qualitative data analysis: For the top 68 agencies, a qualitative textual genre analysis was carried out by analysing wall posts on the agency FB pages. The aim was to understand the communicative practices so that agency and audience engagement can be assessed.

- Stage 3 Online Survey: Distribute a survey to government social media 
communicators to develop anecdotal feedback on efficiencies, challenges and risks.

This paper reports on the findings from stage 1 on posts and interactions on government Facebook Pages.

\section{Data Collection}

Using FB API through the services of a third party mining tool CrowdTangle, FB wall post data for 147 Australian federal government agencies data were collected. The agency list was compiled from official government portals (i.e. australia.gov.au and data.gov.au). To the best of our knowledge, these sites list the current federal agencies that have an active FB page. Using FB API, page post activity and interactions data was collected for three years (Jan 2013-Jan 2016). These are all publicly available data from those pages. The dataset was compiled from Jan 2013 through to Jan 2016, giving data points for 37 months which resulted in a large database of post usage data for federal government agencies. Overall the data included monthly posts by type (link, video, status, photo and native video); interactions on posts (likes, shares and comments), page likes (i.e. fan size), page growth, post frequency etc. There were 114,625 posts collected over the study period. The 114,625 posts received $94,063,698$ interactions which included $74,990,295$ likes, 2,749,721 comments, and $16,323,682$ shares. Total number of fans across these 147 Pages was 12,752,815. The dataset further included time of posts (e.g. day, date, month, and year), description of the post (e.g. actual message) and link to the post (e.g. final link, link and link text).

\section{Analysis Method}

When defining the scope of an engagement it is important to identify both the type of use desired and the level of engagement expected from the initiative (Au, 2010). Moreover measuring SM engagement is critical for successful implementation, yet there is lack of standard measure for such task (Chang \& Kannan, 2008). Mergel (2013b)'s framework for social media impact includes metrics, procedures and outcomes to measure and interpret social media use in the public sector. Furthermore Au (2010) asserts that it is important to distinguish between audience and organisational engagement to understand the level of engagement evident in an initiative. Au (2010) states that measuring audience engagement and the effectiveness of web 2.0 tool has a high level of difficulty. In his report, Au (2010) presents a case of measuring SM engagements and effectiveness of Government Agency pages by using quantitative measures, such as the number of visitors. Hence we further extend Mergel's framework to include audience and agency engagement. For this study we define 'agency engagement' as the post activity by the government agencies and 'audience engagement' is measured as interactions by fans (likes, shares and comments) on government posts. This study will use both audience and agency engagement as a measure of level of engagement seen in the FB pages. A cursory investigation on a random sample of Facebook pages also found that there are very limited fan posts on government pages (for most they are non-existent). Fans mostly interact through the like, share and comments feature. Hence these mechanics were identified to measure audience engagement.

Against this backdrop, first the agencies were classified into four types based on their functionality according to the classification used in the State of the Service report 2014-15 by the Australian Public Service Commission (APSC, 2015) (see Table 2). The majority of Australian Government Facebook Pages, per APSC classification, are managed by Operational Agencies. 


\begin{tabular}{|l|l|}
\hline Table 2 - Government Facebook Pages and agency classification \\
\hline $\begin{array}{l}\text { Operational: } \\
\text { (75 Pages) }\end{array}$ & $\begin{array}{l}\text { Organisations involved in the implementation of public policy } \\
\text { includes Smaller Operational (under 1,000 staff) \& Larger Operational } \\
\text { (over 1,000 staff) } \\
\text { (e.g.: Australia in the Caribbean, Royal Australian Navy, Screen } \\
\text { Australia, Bureau of Meteorology, Australian Tax Office) }\end{array}$ \\
\hline $\begin{array}{l}\text { Policy: } \\
\text { (8 Pages) }\end{array}$ & $\begin{array}{l}\text { Organisations involved in the development of public policy } \\
\text { (e.g.: Headspace, Australia's Chief Scientist, business.gov.au, Safe } \\
\text { Work Australia, AusIndustry) }\end{array}$ \\
\hline $\begin{array}{l}\text { Regulatory: } \\
\text { (18 Pages) }\end{array}$ & $\begin{array}{l}\text { Organisations involved in regulation and inspection } \\
\text { (i.e.: Australian Maritime Safety Authority, Great Barrier Reef Marine } \\
\text { Park, ASADA) }\end{array}$ \\
\hline $\begin{array}{l}\text { Specialist: } \\
\text { (46 Pages) }\end{array}$ & $\begin{array}{l}\text { Organisations providing specialist support to government } \\
\text { (e.g.: The Line, Australian Parliament - House of Representatives, } \\
\text { DonateLife, Questacon) }\end{array}$ \\
\hline
\end{tabular}

Then comparison was carried out using Excel with an aim to explore for similarities and differences in engagement patterns across the four types of agency:

- Agency engagement: Patterns of usage of posts by types (i.e. photos, videos, status, links)

- Audience engagement: Interaction types across post types (i.e. likes, shares and comments)

\section{Findings}

\section{Fan Size and General Observations}

Among the 147 agencies, there are 75 operational, 46 specialist, 18 regulatory and 8 policy agencies. The operational and specialist agencies are leading in terms of fan size measured as page likes. There are 26 specialist and 20 operational agencies among the top 50 agencies by fan size. However if we consider the total volume of fans, then operational agencies have the most major share size of fans. There is only one policy and three regulatory agencies in the top 50 by fan size. Overall there are multiple Australian embassies in this top leaderboard chart. This might be due to the large population in those countries and their interest in Australia as a country to either visit or migrate.

The median fan size for all agencies is 15,738 . This fan base is concentrated Australia.com has 6.6 million fans and the top 10 Pages together account for $74 \%$ of these fans. The smallest 100 Pages collectively only account for $7 \%$ of the total fan base. There is a modest upward trend in fan growth among the pages. According to Mergel (2013b), the number of fans participating in these pages is indicative of the goal of agencies in successfully disseminating information for accountability through Facebook pages.

\section{Agency Engagement based on Post Activity}

Agency engagement is measured in terms of post activity on FB sites which has implications for level of participation (Mergel $2013 \mathrm{~b}$ ). In total, the federal agencies have published over $1.5 \mathrm{~m}(1,53,812)$ posts over the last three years. During this time 77,336 photos, 11,489 videos, 9,055 status posts, and 55,932 numbers of Links were shared on the FB sites. Photos and links are by far the most popular type of post, which is also representative of the trends in FB sites in general. In terms of total number of posts posted by agencies over the last three years, specialist (53084) and operational (56960) 
agencies are actively engaging in FB with more posts than the regulatory (9919) and policy (8062) agencies. Hence operational agencies are leading with agency engagement.

Overall there is a steady growth in the cumulative number of posts made by federal agencies. From 2013 to 2016 there was a more than a 150 percent increase in posts across the 147 Pages. That means agency engagement has been growing due to the mandate by the Australian government to engage with citizens. Overall the ratio across different types of posts remains the same - majority of the posts are photos, followed by links, videos and status posts. Average post frequency is 0.69 indicating less than one post per day. The top 10 Pages accounted for only 13\% $(15,546)$. However, the top 74 Pages $(50 \%$ of the total analysed) accounted for $68 \%$ of posts $(78,488)$, leaving the implication that posting level did positively influence fan engagement implying that in terms of Mergel(2013b)'s engagement impact, post activity increases fan participation.

As evidenced in the data (see Figure 1), the agencies differ both in terms of number of posts and type of posts they publish. Operational and regulatory agency posts have increased considerably over the last three years, whereas specialist agency post growth has been more consistent. This is because specialist agencies were already regularly using social media due to the nature of their business, whereas operational and regulatory agency may have started to engage actively due to the recent mandate by open government directive. Interestingly, policy agencies posts decreased over this timeframe. This can be due to only a small number of agencies in our dataset (only 8 agencies from a pool of 147 agencies) or not much engagement was required by these agencies.

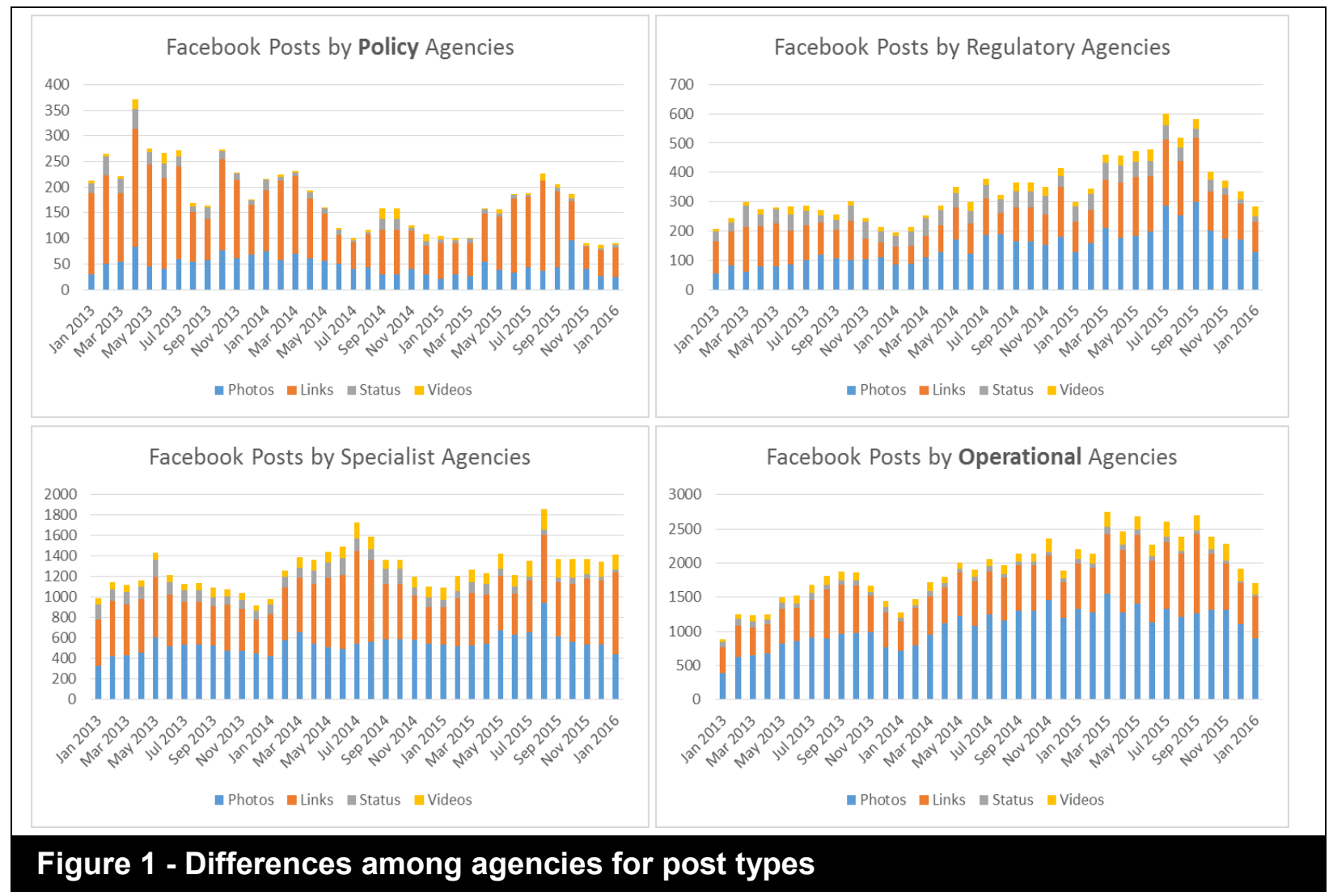

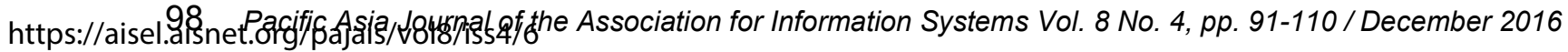


In terms of quantity of posts, interestingly operational agencies lead the board; on an average they post 1925 posts per month. Second in the leader board is specialist agencies, publishing on an average 1279 posts per month. On the other hand, as expected regulatory agencies publish on an average 340 posts and policy agencies publish on an average 278 posts; these are significantly less in terms of quantity of posts per month as compared with operational and specialist. This has implications for Mergel (2013a)'s participation level. Regulatory and policy agencies are receiving less interaction from its audience (Mergel, 2013a).

There is a tendency that operational agencies are posting more pictures than other agency types. This is interesting as one would expect that specialist agencies, which are mostly information and news and cultural based, may be posting more pictures. In terms of Video posts (includes both FB videos and other videos) and Link posts, agencies are divided into two group patterns:

1) Policy and regulatory agencies exhibiting similar behaviour.

2) Specialist and operational agencies exhibiting similar behaviour with Operational agencies sharing more links in recent times.

In terms of uploading status posts, all agencies demonstrate similar behavior with specialist agencies leading the board. However an interesting observation is that status posts exhibit a decreasing tendency over the years. This may be attributed to the fact that most FB posts are now accompanied by photos, a common practice across the field. Again this has implications for level of engagement and impact (Mergel, 2013b). To increase participation, agencies need to use more visual communication rather than text based communication.

\section{Audience Engagement based on Interaction Types}

Audience engagement is measured in terms of number of likes, shares and comments on government posts which has implications for participation and collaboration level (Mergel, 2013). Volume of interactions over three years have been impressive with interactions including $7,77,02,178$ of likes, $1,70,02,648$ of shares and $30,33,969$ of comments. On average federal agencies receive $21,00,059$ of likes, 4, 59,531 of shares and 81,999 of comments per month.

Hence there is a clear trend in interaction types. There are more likes $(75 \%)$ than shares $(18 \%)$ and comments (6.5\%). Comments are very low across the agency types. If we take Mergel (2013b)'s suggested mechanics to measure social impact through level of engagement, then these findings imply that agencies are engaging in low level of participation without any evidence of real dialogue. This also seems to support that the social impact of agency use of Facebook is not resulting in real collaboration. The findings further reflects that agencies still predominantly treat their Facebook Pages as outbound marketing and communications channels rather than places for serious discussions of difficult and controversial topics.

There are considerable differences in patterns of interaction for agency types as can been in Figure 2. As par volume of interactions, the ranking of agencies is operational, specialist, regulatory and policy in decreasing order. Overall operational agencies experience larger share of interactions with over 288,828 likes, 52795 shares and 16617 comments. There is a significant exponential growth in their interactions which shows that citizens are much more engaged with operational agencies. Specialist agencies also experienced growth over the years, but significantly less than operational. Regulatory agencies started slower than other agencies, but since 2014 have been slowly growing interactions with public. 
Policy agencies started later as well, but there is no pattern evident in their interactions with public. In terms of social impact (Mergel, 2013a); hence policy agencies are attracting the least amount of participation.

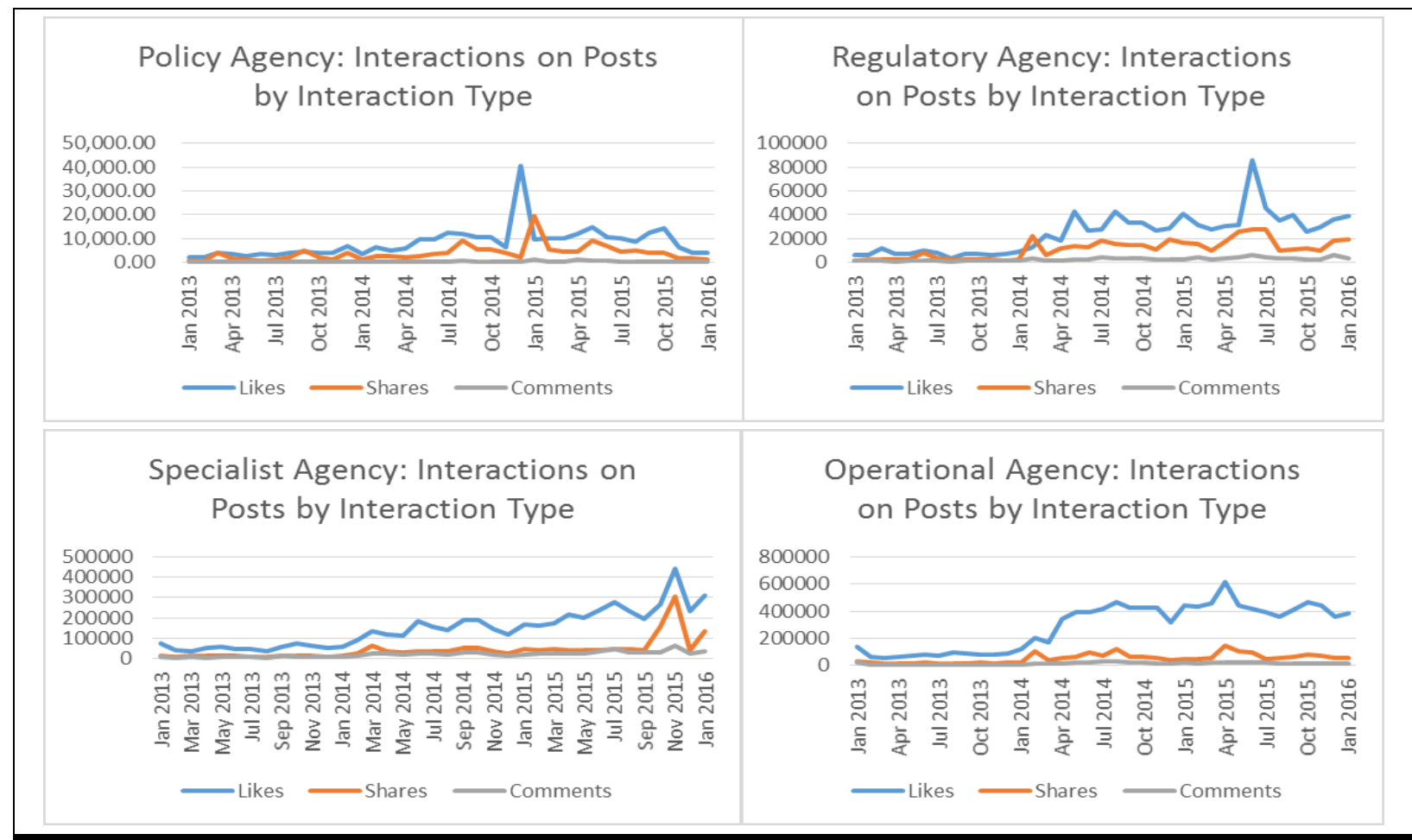

Figure 2 - Differences among agencies by interaction types

\section{Discussion}

\section{Median fan size, Page interactions and type of posts}

Based on analysis it can be concluded that different types of agencies demonstrate different agency and audience engagement patterns implying varied level of engagement and social impact as par Mergel's framework. Operational agencies have been found to be the most engaged both in terms of agency and audience engagement implying participation level of engagement. They are also delivering the best return on conversations as evidenced in their activity per post and interaction rates. This is an interesting finding, as it was expected that specialist agencies would be more active than operational agencies. There is a common tendency in terms of performance across these agencies. The ranking of these agencies are: 1) operational 2) specialist 3) regulatory and 4) policy in most categories. There is an inclination that operational and specialist agencies engagement pattern is similar whereas regulatory and policy agencies engagement pattern is similar (see Table 3). This implies that operational and specialist agencies are showing higher level of participation than policy and regulatory agencies. All of the agencies showing very low level of evidence for collaboration.

In summary, Policy type Pages achieved a far higher interaction rate than any other type, suggesting that these agencies were more interested and committed to soliciting user feedback. Specialist Pages had the largest audiences on average, and also made greater use of video, which reflects the particularly high sharing and commenting rates. Operational pages used 
the most photos, which stimulated the highest level of likes, but lower sharing and commenting rates than video posts.

\begin{tabular}{|l|c|c|c|c|c|c|c|c|}
\hline \multicolumn{2}{|c|}{ Table 3 - Comparison of posts and interaction across agency types } \\
\hline $\begin{array}{c}\text { Agency } \\
\text { Type }\end{array}$ & count & $\begin{array}{c}\text { Median } \\
\text { fan } \\
\text { size } 1\end{array}$ & $\begin{array}{c}\text { Total } \\
\text { posts } \\
\text { per } \\
\text { page }\end{array}$ & $\begin{array}{c}\text { Average } \\
\text { posts } \\
\text { per } \\
\text { page } \\
\text { type }\end{array}$ & $\begin{array}{c}\text { Activity } \\
\text { per } \\
\text { post }\end{array}$ & $\begin{array}{c}\text { Average } \\
\text { daily } \\
\text { posts }\end{array}$ & $\begin{array}{c}\text { Total } \\
\text { Interactions }\end{array}$ & $\begin{array}{c}\text { Average } \\
\text { interactions } \\
\text { per page } \\
\text { type }\end{array}$ \\
\hline Operational & 742 & 15,738 & 73,384 & 1005 & 188 & 0.90 & $13,785,522$ & 188,842 \\
\hline Specialist & 46 & 18,010 & 49,042 & 1066 & 164 & 0.95 & $8,026,604$ & 174,491 \\
\hline Regulatory & 18 & 14,100 & 12,961 & 720 & 114 & 0.64 & $1,482,464$ & 82,359 \\
\hline Policy & 8 & 6,583 & 6,787 & 848 & 70 & 0.76 & 477,228 & 59,653 \\
\hline
\end{tabular}

\section{Posting trends by Page}

In terms of post quantity, Operational agency Pages were at the top of the leader board (see Table 4). Operational agencies posted on average 334.93 times per Page in 2015, approximately double their posting rate in 2013. Next were Specialist agency Pages, which published an average of 311 times per Page in 2015, an increase of $25 \%$ over 2013. Regulatory agency Pages were significantly behind, publishing only an average of 228.94 times per Page in 2015, albeit a larger percentage increases from 2013 than for Specialist agencies at about $80 \%$. Policy agency Page posting declined from 2013 to 2015, from 224.38 posts on average per Page in 2013 and only 174.88 times per Page in 2015, a reduction of $20 \%$ and only half the rate of Operational agency Pages.

Overall there has been an increasing tendency in post activity and interactions on FB pages across all agency types. Operational and Regulatory Page posts per month increased considerably (almost doubled) over the study period, whereas Specialist Page post rate growth was more restrained (20\% increase). This could be because Specialist agencies were already consistently using their Pages in their operations, whereas Operational and Regulatory agencies are building their internal mandates and progressively increasing the extent of topics they engage with on their Pages. Interestingly Policy agency Page posts per Page per month decreased over the three-year analysis period, falling from 18.7 posts per month in 2013 to 14.57 posts per month in 2015. There was no clear rationale in the data for this reduction, but total interactions with Policy pages did increase over the three years analysed. Again while there are only eight Policy agencies within the sample, there are indications that while these agencies generate the highest level of interaction by fan, they either are not seeking to engage the public in policy development, or do not yet see their Pages as an effective tool for this type of engagement activity.

\footnotetext{
${ }^{1}$ Note that Median was used for fans, rather than average, as the large variation in fan numbers made the averages significantly higher and within the top $10 \%$ of pages for each Type. For reference the average fans per type were as follows, Operational: 46,929, Policy: 21,091, Regulatory: 33,097, Specialist 39,622.

2 Due to the size and activity in the Australia.com Page, which significantly distorted statistics for Operational Pages, it was excluded from the analysis (hence only 74 Operational Pages).
} 


\section{Table 4 - Agency type post leader board (2013-2015)}

\begin{tabular}{|c|c|c|c|}
\hline Rank / Year & $\mathbf{2 0 1 3}$ & $\mathbf{2 0 1 4}$ & $\mathbf{2 0 1 5}$ \\
\hline 1 & Specialist (248.39) & Specialist (273.50) & Operational (334.93) \\
\hline 2 & Policy (224.38) & Operational $(249.04)$ & Specialist (311.00) \\
\hline 3 & Operational (184.35) & Policy $(219.00)$ & Regulatory (228.94) \\
\hline 4 & Regulatory (128.50) & Regulatory $(160.61)$ & Policy (174.88) \\
\hline
\end{tabular}

\section{Posting trends by type of post}

There has been a clear shift in the type of post agencies has posted to their Facebook Pages over the years. The difference becomes even more obvious when grouping visual (photo and video) and textual (link and status) posts (see Figure 3). Operational Pages made significantly more use of visual imagery than any other category. Top Pages tended to publish more visual (photo/video) posts. Video and photo postings have grown significantly faster than link postings, while the number of status posts has actually declined. At least eighty percent of over performing posts (i.e. posts with more than 1000 interactions) made significant use of imagery. Native Facebook video use has grown exponentially over the three years, more than quadrupled. Policy agencies share more links, whereas operational agencies post more status posts with photos.

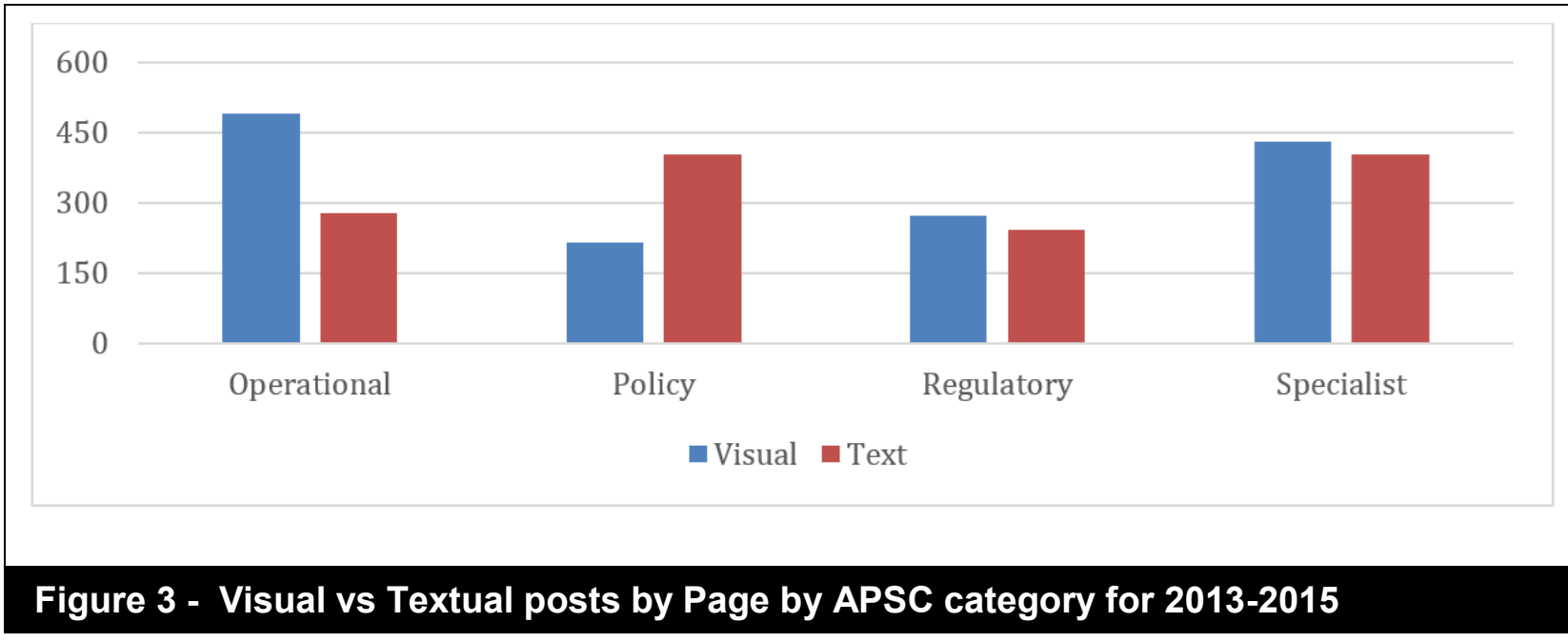

Given Operational Pages have been more successful than others at attracting both fans and interactions per Post, even though on average their fans are far less engaged than fans on Policy Pages, there was evidence of a significant correlation between photo posts and engagement levels.

Specialist agencies, who posted more photos per Page than Operational pages in 2013, have failed to keep up with this growth, or with the growth rate for
Regulatory agencies, despite in many cases owning extremely photogenic content and having a strong need to provide information to their audiences. This could be resourcerelated, with Specialist agencies generally having smaller budgets and head counts on average than Operational agencies.

At the other end of the scale, Policy agencies lifted their photo posting rate from 2013 to 2014, but saw a decline in 2015, where they barely posted more images on average per Page than Regulatory agencies 
in 2013. Again while there are only eight Policy agencies within the sample, there are indications that while these agencies generate the highest level of interaction by fan, they either are not seeking to engage the public in policy development, or do not yet see their Pages as an effective tool for this type of engagement activity.

It is notable that Policy agencies have historically made significantly more use of link type of post than other agencies, and led other agencies in their use until 2015. However, link posts, being text-based, are predominantly used to link back to website content, as such they take audiences out of the interactive Facebook Page environment usually back to static websites or videos. They are an informational tool, but not an engagement tool. As such agencies seeking high levels of interaction should seek to reduce their use of links, whereas agencies focused on information provision should make much greater use of them.

Video is a significant and growing area for online, and agencies who wish to remain effective in engaging their audiences will need to continue to grow their capabilities in this type of medium. With the barriers to video online now incredibly low, with $H D$ video possible from smartphones, and Facebook Live designed to make it simple to quickly record live and recorded video, agencies no longer require significant investment or skills to make use of this medium effectively. This is likely to be the area in which agencies grow their engagement most rapidly over the next five years.

\section{Content by Page}

A bias towards visual posting was evident in the content of posts from Pages with greater fan counts. Overall it was interpreted that content in the top Pages was more outwardly focused towards encouraging audience interaction, with more outwardlyengaging language used to draw people into sharing content and commenting. Table 5 compares the top five words commonly used in agency posts across APSC types and color coding have been used to highlight top words in each APSC category (e.g. green for policy, red for operational). The words used most commonly in posts ranged from external-audience and action orientated, such as 'innovation', 'world' and 'news' to more international and defense orientation, such as 'navy', 'airforce', and 'business' to service delivery orientation using technical and bureaucratic language such as 'check', 'safety, 'food and 'support'. Content in regulatory and policy Pages focused on communicating and delivering customer service, addressing user concerns and communicating information needed to access services. Content in specialist agencies as expected, which includes news and media based agencies, included $A B C$ and news as top words. Operational Pages also had 'news' as top word. Regulatory and specialist had a focus on national aspects with common top word as 'national'. Policy and regulatory had a focus on communicating concerns and measures around 'safety' and 'business'.

In the following sections, content trends for each APSC type are discussed.

\section{Operational}

These Pages showed a clear focus on more operational-style informational content, such as the presentation of photos, information related to specific years and defencerelated content. International and local news were also significant and these pages included more technical self-references to Facebook and posts, as well as to program and support/help information than the other categories. Operational Pages posted more photos $(56 \%)$ than other categories but were less likely to link to information (34\%). were moderate users of video $(7 \%)$ but the least likely to make status posts (3\%).

\section{Policy}

Policy pages exhibited a significant focus on business, with areas such as workplace safety and mental health (headspace) being distant second-level topics. Other topics were evenly spread, however some of the 
big policy topics by department, such as health, education, social services, science or environment, received little mention on these pages, suggesting that policy conversations were not significantly involving the public through this channel. Policy Pages posted far fewer photos (31\%) and videos $(4 \%)$ than other categories but were most likely to link to information (59\%). They were light users of status posts (3\%).

\section{Regulatory}

These Pages clearly focused on regulatory matters, particularly related to product recalls, food and safety information. Less significant topics included business, borders, the Great Barrier Reef, the Murray Basin, standards, health and water, all topics expected from regulatory pages. Consumers, people, rights and industry were less commonly mentioned, and were clearly not targeted topics for these pages. Regulatory Pages made the most use of status posts $(12 \%)$ and were low users of links (34\%), but moderately used both photos $(47 \%)$ and videos $(7 \%)$. Of all the categories these Pages appeared most focused across the core goals of their owning agencies.

\section{Specialist}

The Specialist category includes a collection of highly disparate agencies, and this was evident through the terms used in posts on their Pages. Behind a focus on national and news, innovation was a particularly strong term used in posts. Past this were a more eclectic range of terms, from the world and people, to science, advice and exhibitions and the only clear themes were around innovation and travel advice. Specialist Pages made the most use of video $(8 \%)$ and were moderate users of other post types - photos (43\%), links (41\%) and status $(8 \%)$.

\section{Table 5 - Comparison between top five word use frequencies by APSC Type ${ }^{3}$ (colour coding has been used to highlight top five words for each APSC type)}

\begin{tabular}{|l|r|r|r|r|r|}
\multicolumn{1}{|c|}{ Word } & \multicolumn{1}{c|}{ Specialist } & \multicolumn{1}{c|}{ Regulatory } & \multicolumn{1}{c|}{ Policy } & \multicolumn{1}{c|}{ Operational } & \multicolumn{1}{c|}{ Total } \\
\hline abc & 12309 & 133 & 80 & 1666 & 14188 \\
\hline news & 5152 & 428 & 557 & 5797 & 11934 \\
\hline business & 1110 & 1017 & 6066 & 2928 & 11121 \\
\hline national & 5490 & 847 & 540 & 3888 & 10765 \\
\hline photos & 2217 & 706 & 56 & 7168 & 10147 \\
\hline world & 2929 & 422 & 325 & 5815 & 9491 \\
\hline airforce & 321 & 153 & 9 & 8151 & 8634 \\
\hline people & 3176 & 535 & 446 & 4213 & 8370 \\
\hline check & 1955 & 924 & 800 & 3889 & 7568 \\
\hline navy & 150 & 26 & 1 & 7375 & 7552 \\
\hline work & 2176 & 616 & 1734 & 2648 & 7174 \\
\hline help & 1717 & 550 & 1122 & 3159 & 6548 \\
\hline innovation & 3704 & 13 & 373 & 410 & 4500 \\
\hline safety & 462 & 1612 & 1184 & 608 & 3866 \\
\hline food & 684 & 1955 & 67 & 1012 & 3718 \\
\hline
\end{tabular}

\footnotetext{
${ }^{3}$ The terms 'Australia', 'Australian' and 'gov' and 'government' have been excluded from word clouds due to being most used across all segments. Common words (e.g. pronouns, adjectives) were also excluded from word cloud analysis.
} 


\section{Mergel's Interaction Level and Agency Types}

The progressive shift towards visual content, increasing posting frequency and changes in the terminology and topics that agencies have posted about in their pages has seen a trend for increased interactions per post. Interactions per post grew significantly across all types (Likes, Shares, Comments) from 2013 to 2016, seeing almost six times increase in total interactions per post on government Facebook Pages. The data indicates Australians have become more comfortable engaging with government via social networks as well as that agency has significantly improved the quality and shareability of their posted content.

In terms of Mergel's (2013a) framework of social impact, all agencies have successfully used Facebook for transparency and accountability. Operational agencies have shown highest level of participation, followed closely by Specialist agencies. Regulatory agencies have shown low level of participation with regulatory agency showing minimal level of participation.

There is a clear trend that there are more likes $(75 \%)$ than shares $(18 \%)$ and comments $(6.5 \%)$. This finding reflects that agencies still predominantly treat their Facebook Pages as outbound marketing and communications channels rather than places for serious discussions of difficult and controversial topics.

\section{A Neo-Institutional Perspective to Agency Types}

The neo-institutional models discussed earlier can provide further explanations to the differences observed among agency types based on their functional focus operational, policy, regulatory and policy. As Criado, Rojas-Martin and Gil-Garcia (2017) showed in their research that certain aspects of organizational, environmental and institutional factors influenced the adoption, implementation and use of social media in local public administrations. We also assert that these factors as manifested within the four APSC agency types can help us with sense-making. Due to the nature of institutional and environmental factors within policy and regulatory agencies which focuses on disseminating information on policies and regulatory processes, the posts are thus status and link posts that links to the source of information. The interactions regulatory agencies receive are shares whereas policy agencies may receive both likes and comments. Operational agencies have the dual role of information dissemination and delivering services. They thus use more visual posts (e.g. photos or videos) that explain/remind/inform about various services and processes citizens need to access their services. Specialist agencies include news and cultural institutions that are likely to promote their events and collections. Hence they use more photo and link posts and receive both likes and shares. It is out of scope for this paper to delve further into the influencing factors that differentiate the four APSC types, but this research has shown that extended EEGS model does provide an analytical framework to explain some of the variances.

\section{Implications for Research and Practice}

For successful engagement both audience and organisation involvement work as enablers of participation and collaboration. Simply posting and interacting on FB to support online participation is unlikely to create an adequate solution. So this research contributes to understanding the nature of popular post types and engagement in government FB pages to make an informed decision about social strategy.

This study tried to ascertain if there is any difference among agency types in relation to agency post activity and audience interactions. Using Mergel's (2013b) framework of social impact for social media 
interactions, we have observed from findings above that there are considerable differences among agency types. The study unfolded key insights on audience engagement across government posts which is useful for government social media practitioners and communicators to formulate social media interaction strategies. To sum up:

- Pages with more fans tended to be more frequent posters, and suggest that more frequent posting is a key to building and maintaining a larger fan base.

- Photos and videos or visual content attract greater levels of interaction.

- Government Facebook Pages with fewer fans consistently evidenced significantly lower posting rates, less use of visual content and more bureaucratic and agency-centric language in their posts.

- Agencies seeking high levels of interaction should seek to reduce their use of links, whereas agencies focused on information provision should make much greater use of them.

- To attract fans, content should be devised more outwardly focused to encourage audience interaction, but with more outwardly-engaging language used to draw people into sharing content and commenting.

In summary, the key contributions of this study are threefold. Firstly, the research contributes to gaining a better understanding of government FB phenomenon at federal level from demand side perspective to citizen interactions on government posts, in particular for Australian context. This study provides original primary data based on world-first largest scale study at federal government level and contributes to the growing field of study in demand side perspective, as most existing research emphasises the supply side or theoretical conceptualisation. Secondly, the research reveals that varied level of engagement is visible within these Pages relative to audience and organisational engagement in terms of Mergel's three levels of interactions. The insights from analyzing the government Facebook Pages in this research suggest that agencies remain largely focused on broadcast and basic interactions with audiences - using Facebook to provide information and respond in a limited way to citizen questions or complaints. This controlled and managed approach may suit risk-averse agency structures, but in many cases results in sub-optimal performance and ignores many of the potential benefits that social media, in particular Facebook, offer for agencies that require deeper and more sustained engagement with citizens and stakeholders. Thirdly, differences were observed in agency engagement (post activity) and audience engagement (interaction) across different types of agencies based on their functional focus (i.e. policy, regulatory, operational and specific).

\section{Research Limitations and Future Research}

Some caution should be noted when interpreting the results agency classification and usefulness of observed differences. Even though the FB Pages were classified based on the agency that operated and/or funded them, using the Australian Public Service Commission's State of the Service report 2014-20154; These categories, while useful for benchmarking broad agency performance, did not consistently relate to the purposes or use of individual government Facebook Pages and proved to not be useful in analyzing activity. Hence even though we observed differences, they should be treated with caution. It should be also noted that the classification used in this study thus may not be useful to differentiate between government FB Pages. As such a custom classification system based on Page

\footnotetext{
${ }^{4}$ APSC State of the Service Report 2014-15 (apsc.gov.au/about-theapsc/parliamentary/state-of-the-service/state-ofthe-service-report-2014-15)
} 
audience (domestic or international) and goal (behavior change, information provision, cultural objectives or media) may be a useful mechanism to differentiate the government Pages. This sort of classification may prove to be more effective in grouping and benchmarking how and why agencies engaged through their Facebook Pages and the likely outcomes they achieved from this engagement. Furthermore though this APSC classification is based on Australian context and is used in government reports, it should be noted that it is not readily transferable to other countries or contexts of public administration.

This study presented the aspects of posts and citizen interactions from a descriptive perspective. An avenue for future research in this study is to carry out further analysis of the data to test the intended hypothesis of this study - if different government agency types may lead to different interactions and posting behaviour. For example, mean differences can be used to test the significance of differences among different types of agencies (e.g. ANOVA or F-test). We hope this will yield if the observed differences reported in this report were statistically significant. This further analysis may reveal and confirm our assertion that APSC category may not be best approach to classify the government FB Pages.

There are further limitations in this study. The types of engagement activities have been identified based on information on publically available FB pages. The research does not take into consideration the barriers to engagement. Future studies can also use Social Network Analysis (SNA) tools to understand audience engagement and its value and outcomes.

The study is yet to conduct the survey and gather evidence from the organisation to make further conclusions. The metrics for engagement used in this paper are limited and based on available online wall posts. More metrics will be included in future research such as further engagement metrics, more qualitative data about alignment, outcomes and benefits realisation through survey.

\section{Acknowledgements}

This research has received funding from Facebook Inc. and had employed research assistants to carry out the quantitative data collection and analysis. An earlier version of this paper was presented at the International Conference in Information Systems (ICIS 2016) as research-inprogress publication. I would like to thank the reviewers from both ICIS 2016 and PAJIS special issue for their helpful suggestions to improve the paper.

\section{References}

Abdelsalam, H. M., Reddick, C. G. and AlShaar, A. (2013). "Social Media in Egyptian Government Websites: Presence, Usage, and Effectiveness," Government Information Quarterly, 30(4), pp. 406-416.

Alam, S. L. and Diamah, A. (2011). "Understanding User Participation in Australian Government Tourism Facebook Page," in Proceedings of the 23rd Australasian Conference on Information Systems, pp. 77-88.

Alam, S. L. and Walker, D. (2011). "The Public Facebook: A Case of Australian Government Facebook Pages and Participation," in Proceedings of the Australasian Conference of Information Systems 2011. Retrieved from http://aisel.aisnet.org/acis2011/3.

Alam, S. L., Campbell, J. and Lucas, R. (2011). "Using Social Media in Government: The Australian Tax Office e-Tax Facebook Page," in Proceedings of the 9th IEEE International Symposium on 
Dependable, Autonomic and Secure Computing 2011, pp. 1002-1009.

Al-Wahaibi, H. A., Al-Mukhaini, E. M., AlBadi, A. H. and Ali, S. (2015). "A Case Study of the Employment of Social Media in Government Agencies in Oman," in Proceedings of the IEEE $8^{\text {th }}$ GCC Conference and Exhibition, pp. 1-6. Retrieved from ieeexplore.ieee.org/xpl/articleDet ails.jsp?arnumber=7060089.

Au, Andrea, (2010). Adoption of Web 2.0 by Tourism Businesses in NSW. January 2010

APSC. (2015). State of the Service Report 2014-15. Available online at http://www.apsc.gov.au/about-theapsc/parliamentary/state-of-theservice/state-of-the-service-report2014-15

Chang, A \& Kannan, P. (2008). Leveraging web 2.0 in Government, Industry research paper

Chun, S. A. (2012). "Social media in government," Government Information Quarterly, 29(4), pp. 441-445.

Collins, S. (2009). "Culture in the New Order", Upgrading Democracy, Insight Edition, Centre for Policy Development, Sydney NSW, viewed 30 April 2016: cpd.org.au.

Creswell, J. W., \& Clark, V. L. P. (2007). Designing and conducting mixed methods research (pp. 275). Thousand Oaks, CA: Sage publications.

Criado, J. I., Rojas-Martín, F. and Gil-Garcia, J. (2017)." Enacting social media success in local public administrations: An empirical analysis of organizational, institutional, and contextual factors ", International Journal of Public Sector Management, 30(1), pp. 31 - 47

Criado, J. I., Sandoval-Almazan, R. and GilGarcia, J. R. (2013). "Government Innovation Through Social Media,"
Government Information Quarterly, 30(4), pp. 319-326.

Digital Transformation Office (DTO). (2009). Government Response to the Report of the Government 2.0 Taskforce 'Engage: Getting on with Government 2.0', viewed 12 September 2016, http://www.finance.gov.au/publications /govresponse20report/index.html

Dixon, B. E. (2010). "Towards eGovernment 2.0: An Assessment of Where e-Government 2.0 is and Where it is Headed", Public Administration and Management, 15(2), pp. 418-454.

Fountain, J.E. (2001). Building the virtual state: information technology and institutional change, Brooking Institution Press, Washington, DC

Gil-Garcia, J.R. (2012). Enacting electronic government success: an integrative study of government-wide websites, organisational capabilities and institutions, Springer, New York, NY

Hartmann, S., Mainka, A. and Peters, I. (2013). "Government Activities in Social Media," in Proceedings of the 2013 International Conference for eDemocracy and Open Government, pp. 173-186.

Heaselgrave, F. and Simmons, P. (2016). "Culture, Competency and Policy: Why Social Media Dialogue is Limited in Australian Local Government", Journal of Communication Management, 20(2), pp. 133-147.

Hofmann, S., Rackers, M., Beverungen, D. and Becker, J. (2013). "Old Blunders in New Media? How Local Governments Communicate with Citizens in Online Social Networks," in Proceedings of the 46th Hawaiian International Conference on System Sciences, pp. 2023-2032. Retrieved from

http://dx.doi.org/10.1109/HICSS.2013. 421. 
Howard, A. E. (2012). Connecting With Communities: How Local Government is Using Social Media to Engage with Citizens. ANZSOG Institute for Governance at the University of Canberra and Australian Centre of Excellence for Local Government.

Kavanaugh, A. L., Fox, E. A., Sheetz, S. D., Yang, S., Li, L. T., Shoemaker, D. J., Natsev, A. and Xie, L. (2012). "Social Media Use by Government: From the Routine to the Critical," Government Information Quarterly, 29(4), pp. 480491.

Lee, S. T. (2014). "A User Approach to Dialogic Theory in a Facebook Campaign on Love and Marriage," Media, Culture \& Society, 36(4), pp. 437-455.

Lev-On, A. and Steinfeld, N. (2015). "Local Engagement Online: Municipal Facebook Pages as Hubs of Interaction," Government Information Quarterly, 32(3), pp. 299-307.

Linders, D. (2012). "From e-Government to We-Government: Defining a Typology for Citizen Coproduction in the Age of Social Media", Government Information Quarterly, 29(4), pp. 446454.

Mainka, A., Hartmann, S., Stock, W. G. and Peters, I. (2015). "Looking for Friends and Followers: A Global Investigation of Government Social Media Use,"Transforming Government: People, Process and Policy, 9(2), pp.237-254.

Mainka, A., Hartmann, S., Stock. W. G. and Peters, I. (2014). "Government and Social Media: A Case Study of 31 Informational World Cities," in Proceedings of the 47th Hawaii International Conference on System Science, pp. 1715-1724. Retrieved from: arxiv.org/abs/1401.4533.

McKnutt, K. (2014). "Public engagement in the Web 2.0 Era: Social Collaborative
Technologies in a Public Sector Context," Canadian Public Administration, 57(1), pp. 49-70.

Mergel, I. (2013a). "A Framework for Interpreting Social Media Interactions in the Public Sector," Government Information Quarterly, 30(4), pp. 327334.

Mergel, I. (2013b). "Social Media Adoption and Resulting Tactics in the US Federal Government," Government Information Quarterly, 30(2), pp. 123130.

Mossberger, K., Wu, Y. and Crawford, J. (2013). "Connecting Citizens and Local Governments? Social Media and Interactivity in Major U.S. Cities," Government Information Quarterly, 30(4), pp. 351-258.

Reddick, C. G. and Norris, D. F. (2013). "Social Media Adoption at the American Grass Roots: Web 2.0 or 1.5?" Government Information Quarterly, 30(4), pp. 498-507.

Sáez-Martín, A., Haro-de-Rosario, A. and Caba-Perez, C. (2014). "A Vision for Social Media in the Spanish Smartest Cities," Transforming Government: People, Process and Policy, 8(4), pp.521-544.

Samuel, A. (2009). "Waiting for Government 2.0: why do public agencies take so long to embrace social media?" In Gotz \& Pederson (ed.) State of the eUnion: Gov2.0 and onwards, pp. 109-122, 21Gov.net, viewed 20 Oct 2010, http://21gov.net/wpcontent/uploads/e-book.pdf

Skeels, M. M. and Grudin, J. (2009). "When Social Networks Cross Boundaries: A Case Study of Workplace Use of Facebook and Linkedln", In Proceedings of the ACM 2009 International Conference on Supporting Group Work, pp. 95-104. Retrieved from: dl.acm.org/citation.cfm. 
Snead, J. T. (2013). "Social Media Use in the U.S. Executive Branch," Government Information Quarterly, 30(1), pp. 56-63.

Soon, C. and Soh, Y. D. (2014). "Engagement@Web 20.0 between the Government and Citizens in Singapore: Dialogic Communication on Facebook?" Asian Journal of Communication, 24(1), pp. 42-59.

Warren, A. M., Sulaiman, A. and Jaafar, N. I. (2014). "Social Media Effects on Fostering Online Civic Engagement and Building Citizen Trust in Institutions," Government Information Quarterly, 31(2), pp. 291-301.

\section{About the Author}

Sultana Lubna Alam is an Assistant Professor of Information Systems and a research leader of the Digital Transformation service group at the University of Canberra, Australia. Dr Alam completed her $\mathrm{PhD}$ from the University of Canberra on crowdsourcing in non-profit cultural and heritage institutions in 2014. Central to her research is a focus on emerging technologies including social media in public sector, crowdsourcing motivation, technology appropriation and social media in disaster management. She has published in Scandinavian Journal of Information Systems, Australasian Journal of Information Systems, Journal of Systems Education, and Journal of Informatics Education Research. 